\title{
Cultural Heritage in Hungarian Public Education
}

\author{
Krisztina Balázs-Bécsia
}

\begin{abstract}
Like in most European countries, heritage is not integrated centrally to the Hungarian Educational System, yet there are some promising initiatives that can serve as a starting point for best practice share. These initiatives are often taken by World Heritage or other National Heritage sites and always by a bottom-up approach. UNESCO (United Nations Educational, Scientific, and Cultural Organization)'s and HEREDUC (European Union's heritage educational programme supported by the European Commission)'s related projects, as well as numerous others all around the world are aiming at providing a methodology for the introduction of heritage education. Legal background in Hungary encourages schools to integrate site visits into the curriculum but the necessary class time and financing are not provided. Lower grade students participate mainly in the Forest School project and museum visits are also integrated in some schools. Cultural Landscape sites offer the largest choice of outside-the-classroom activities to schools due to the complexity of this type of heritage. According to the author's survey, children are age-appropriately informed of and fairly open-minded about cultural heritage. The key to their empathy is that we do not just have to speak their language but also use the channels they are familiar with, including internet, mobile applications, touchscreens, and social media. The more interactive we make the knowledge transfer, the more we involve them into the creation process, the larger their interest and commitment will be. Therefore, it is our responsibility to determine how prepared and engaged the future decision-makers will be when they will take over this task.
\end{abstract}

\section{Keywords}

Children, culture, education, heritage, interpretation, UNESCO

Despite the commercialisation of tangible and intangible heritage, the children's involvement into the process of safeguarding our heritage remains regrettably low. On long term, this is a dangerous trend as being the forthcoming decision makers, the future of our heritage is depending on their enthusiasm and commitment. The formation of their cultural identity begins in early childhood; therefore, it is advisable to start the heritage education as soon as possible (Bassa 2014). Unfortunately, this field of education is still not granted the due attention, its fulfilment is entirely dependent on the enthusiasm of the teacher. Several international organisations provide heritage educational programmes available to schools and to the authorities both in printed and electronic version. These projects have a long-term, complex approach to integrate the topic into the curriculum.

\footnotetext{
aBudapest Metropolitan University of Applied Sciences, Budapest, Hungary

\section{Correspondent Author:}

Krisztina Balázs-Bécsi, 2143 Kistarcsa, Árpádvezér u. 52/a, Budapest, Hungary
} 


\section{HERITAGE EDUCATION IN HUNGARY}

In Hungary, the legal background of primary education is determined by the National Curriculum set up by the 243/2003 (XII. 17.) Government Regulation. With a mind-set of developing competency based education, it encourages schools and teachers to take advantage of the numerous learning opportunities offered by heritage sites, although the legislature does not provide the necessary class time and funds (Németh 2009). To that end, the insertion of such activities is highly dependent on the teacher's ingenuity and dedication to the matter.

\section{THE FOREST SCHOOL PROJECT}

The Forest School project is by far the most popular among the outside-the-classroom learning activities. This is partly due to the introduction of the National Curriculum which aims at involving every pupil in this kind of activity at least once during schooldays. It is a special session held outside of school, but still it is an integral part of the curriculum. The learning objective in this case is the natural-, built-, and social-environment of the site and the implementation is based on diverse cooperative learning techniques and on the project method (Bilku 2009). In ideal case, the teacher agrees with the programme administrator on the schedule and the objectives and integrates the project in the curriculum of the given academic year. In lower grades, where the subjects are taught by one or two teachers, this task is more feasible; whereas in upper grades, the integration requires a well-intended cooperation of the teaching staff.

During the course of the programme, the students participate in a preparatory session (what will we see?) followed by a field exercise that-besides of increasing their knowledge-will make them familiar with research, observation, botanical and zoological guidebooks, and teamwork. They will be taught to understand correlations, the necessity to comply with certain rules (e.g. to be silent), and to participate in the completion of daily activities that might also serve them at home (production of bird barrow and simple tools and objects). In the author's view, this project's greatest achievement is not the increase in knowledge but the early attitude-shaping effect that helps children to develop respect for their natural and cultural heritage.

\section{MUSEUM VISITS}

The Hungarian State's intention to strengthen the relationship between museums and public education can be traced back to the early 2000s. The institution that coordinates this task is the Museum Education Centre (MOKK) located in the Hungarian Open Air Museum in Szentendre. Its mission is to help museums become more visitor friendly responding to recent trends, as well as to promote competency development in public education by involving museums to the process of education. This new Knowledge Centre's leading project, the "Museums for Everyone" programme aims at creating and developing the culture of learning outside the classroom through the elaboration of new museum educational solutions and at the same time enhancing the cooperation between public schools and museums. To this end, they developed educational programmes for teachers and participated in laying the foundations of a complex legal framework.

As per a recent research conducted by Edit Bárd, schools are using outside-the-classroom activities as a means of getting acquainted with heritage through community experience (Bárd 2009). According to teachers, the main added value of this approach is that it raises pupils' interest towards the topic and makes abstract notions more tangible. Nonetheless, both parties are complaining about the lack of true communication: Teachers are not aware of the wide range of programmes the museums are offering to them, while museums are not conscious of the real 
needs of schools in this field. However, the wider usage of this opportunity would have a positive impact on both sides, as besides the above mentioned advantages for the educational system, museums would also benefit in form of extra services, increasing profit and awareness, but above all these projects help to turn these students into future museum visitors.

\section{INTANGIBLE HERITAGE}

Starting from the academic year 2001/2002, the Hungarian State introduced an ethnographical subject called "Homeland and People" to the 5th-6th grade curriculum. This subject strives for getting the students acquainted with the values of traditional folk culture, thereby protecting them from the negative impacts of consumer society. Although this is a topic that fits into several subjects (history, music, and art history), its introduction did not bring as much success as expected, mainly due to the lack of skilled teachers and training material (Karácsony Molnár and Kraicini Szokoly 1998).

\section{CULTURAL LANDSCAPES IN THE SERVICE OF HERITAGE EDUCATION}

Natural heritage sites and cultural landscapes are more widely involved to public education in Hungary than cultural sites, due to the popularity of the Forest School project. Schools can choose from a variety of high quality programmes offered by the National Parks' network. These programmes are part of a complex environmental educational concept elaborated in line with the given age group's capabilities, as well as with the educational programme stipulated by the National Curriculum. Cultural landscapes in Hungary cover all types of natural habitats offering an insight to the local examples of coexistence of nature and people. Among those, Hortobágy, Fertőtáj, and Tokaj are inscribed to the World Heritage List as such, while parts of the Balaton Uplands National Park (Tihany Peninsula, the buttes of the Tapolca basin and the thermal lake of Héviz) are on the Tentative List. From the variety of environmental educational programmes offered by these sites, the author picked some that she found particularly promising from the point of view of heritage education:

(1) The Wild Watch project fostered by the Ministry of Agriculture nominates an endangered species of mammals each year. In 2015, the chosen mammal was the ground squirrel. The Hortobágy National Park-the Puszta site organised several games and contests relating to this topic for three age groups from preschool to secondary school. Children had the opportunity to test themselves in field exercises as well as in artistic contests, creating drawings, paintings, collage, photos, video clips depicting the ground squirrel, or illustrating relevant poems, writing squirrel-themed essays. The author believes this to be a brilliant initiative as it involves the pupils to several fields of culture at the same time, and thus reaches a broader public. While environmental protection is the guiding topic of the programmes organised by the site, the cultural aspect is also emphasised in educational projects. In Hortobágy, the human side is represented by the shepherd culture including folk music and dance, embroidered costumes, tools and everyday objects, together with the knowledge and craftsmanship that created them. The site's complex environmental education concept intends to make the children understand how this cultural landscape was formed and how it developed over the centuries.

(2) The wetlands left their mark not just on the wildlife but also on the customs and beliefs of the people of Fertö/Neusiedlersee Cultural Landscape. Out of the well-thought-out activities offered by the site, the author would highlight the programme made for preschool and elementary school age groups. At the beginning, children listen to tales about fairies and 
elves that populate the marshlands according to local beliefs. Afterwards, with the help of animators, students make puppets based on the tales and finally they take those puppets to the excursion, where the tale can be acted out. These puppets will also serve as a souvenir helping to revive the memories of the excursion which they can also share with their parents or friends.

(3) The Balaton Uplands National Park developed a complex environmental educational programme for the entire academic year in cooperation with their partner schools. Within this framework, the experts help the teachers with advice, material, and ideas. Among the downloadable worksheets, the one entitled "Roaming in Tihany" is the most closely related to the point of cultural landscapes, inspiring children to focus on the history, famous buildings, and hidden details of the settlement which are integral parts of the landscape for centuries.

(4) Although the Millenary Benedictine Abbey of Pannonhalma and its environment is not inscribed to the List as a cultural landscape, the coexistence of nature, culture, and built environment on this site is so close that it is worth to mention here its educational programmes. Being also an educational institution, the Abbey focuses on the methods of safeguarding and developing the knowledge it accumulated over the centuries. Part of this knowledge is the science of cultivating and using medicinal herbs. The downloadable material-elaborated with the help of the Natural History Museum of Budapest within the framework of the Natural Europe project-is intended to fill natural science courses with interesting facts and to encourage teachers to insert a visit into the curriculum to make it even more tangible.

\section{RESEARCH-STUDENTS' INVOLVEMENT IN SAFEGUARDING OUR HERITAGE}

There are several studies and surveys on heritage education but they mainly concentrate on schools and heritage sites, the awareness and attitude of the students towards the matter is scarcely researched. In the author's view, this is also an important feedback on how the system is operating; therefore the author conducted a survey on this topic in the age group of 10-14 years old students located in Budapest and the surroundings. The 110 students participating in this survey did not attend any special heritage education courses, all their knowledge on the topic was acquired from their families and their enthusiastic teachers, during family or school excursions, history and natural science classes. Before completing the survey, the author had an interactive talk session on Hungarian cultural heritage with 51 students out of the 110. The aim of the author's research was:

(1) To examine their level of awareness of the heritage of their own family and local community;

(2) If the family is keeping its customs, traditions;

(3) If they regularly go on excursions;

(4) If all the above are in close connection with the awareness of the children;

(5) To formulate development proposals.

In order to make the survey more understandable and processable, the author asked closed questions but left room for the students to formulate their ideas and development proposals, revealing their interest and creativity.

The first group of questions is related to their family heritage, both tangible and intangible. The author intended to examine if these families are keen on safeguarding and passing on their heritage to the next generations. Traditions are usually born from practices formed in smaller communities and passed on from generation to generation. This way, even a family habit can be taken over and passed on by a larger community to finally become a tradition. Common traditions give a sense of belonging to the members of the community, therefore it is important to make our children understand that commonly kept habits, visiting relatives, eating, celebrating, and travelling together are important and give a feeling of 
comfort and joy to each member of the family. To the question "Do you have at home any objects, photos, etc. that your family inherited from your ancestors?", $95 \%$ of the students gave a positive reply, while to the question "Did your parents tell you about the history of these objects?", $77 \%$ replied positively. To the question "Is there any feast (Christmas, Easter, anniversary, etc.) that you are celebrating in family each year?", 92\% replied yes. The result shows that safeguarding and passing on their cultural heritage is important to these families, and the fact that $92 \%$ gave a positive reply to the question "Do you know any kind of Hungarian tradition or folk custom?" suggests a close connection between the above and the knowledge of the students in this field.

The next group of questions was intended to inquire on the pattern of family trips. These are the first opportunities for a child to visit a heritage site; and for those whose family goes regularly on excursions, these visits will be a natural fact of life. Once this behaviour is established in family, these children will take cultural heritage in a more open-minded, interested, and sympathetic way on school trips. According to the survey, $89 \%$ of the families take their children regularly to domestic trips and $61 \%$ even take them abroad. The students the author had the chance to meet were pleasingly well-informed on Hungarian World Heritage sites. Forty-two out of the $51(82 \%)$ were aware of the Buda Castle and Banks of the Danube being part of the World Heritage (although there were only three aware of the extension to the Andrássy Avenue); 15 students (30\%) were informed of Hollókő and 15 of the Caves of Aggtelek being inscribed to the List; while the remaining sites were all specified by 1-2 students with the exception of Tokaj. Interestingly enough, the Busó festivities at Mohács was also thought to be on the World Heritage List, apparently it is hard for them to distinguish between tangible and intangible heritage. The $79 \%$ of the students were aware of having visited a World Heritage site, although the author had to highlight that the students participating in this survey were all living in or in the nearby of Budapest, therefore it is likely that the high ratio is partly due to the conflation of the specific World Heritage site with the city itself. The next question strived for revealing the children's preferences in terms of types of heritage. The author listed three types (natural-, built-heritage, and museums) as she was informed by the teachers that all respondents already participated in these types of school trips. The majority of the students preferred city trips $(67 \%)$ and nature tour $(64 \%)$, while museum visits obtained the vote of $44 \%$, this result - to the author's pleasure-exceeded her preliminary expectations. According to the teachers, this might be due to the fact that thematic museum visits are regularly organised and that children enjoy the diverse edutainment type of activities that liven up the visits.

The last part of the survey focuses on interpretation. Based on the usage patterns of this age group, the author assumed that mobile devices are in the focus of their interest. According to the results, it is very much known and expected by students: $91 \%$ already used some kind of digital device (e.g. interactive panels, mobile applications, websites, or $3 \mathrm{D}$ presentation). The particular devices achieved a similar result (47-51\%) with the exception of QR codes and websites (39\%), possibly due to the (non-)reading habits of this generation. Non-digital means of interpretation is also highly (92\%) known by pupils and some of the elements ["games and contests" (59\%) and "crafts and artefacts" (72\%)] achieved a higher score than any of the digital devices. This might be due to teachers' intention to include more of these activities in the course of the visit. Generally speaking, the children use more the digital devices during family trips, while the traditional forms of interpretation are mainly met with during school trips. Finally, the author asked the participants of the survey to give ideas that in their view could improve the experience of a site visit. The author is convinced that knowing their expectations and using their own ideas 
would make the sites more visitor-friendly. Children see things from a different aspect—-both literally and figuratively - and from their point of view, things reveal qualities that remain hidden for us adults. In addition, involving them to the process also means winning their sympathy for the case as they are likely to be tied to the subjects of their examination. Their ideas involve but are not limited to movie presentations in 3D and 4D and a how-it-was-made-video, a hologram display which fits into the vision of the Museum of the Future and which allows to see the exhibited objects from different perspectives, making the display more exciting and easily adaptable to changes. Many of them expect to be able to take the objects (or replicas) in their hands and examine them closely, to touch and smell them as well as to use tools to the purpose they were made for. Reviving the life of people of historical times - mainly that of children-is as popular as to dress up in historical costumes and using old toys.

They expect museum educators to speak their own language, to tell funny and interesting stories about the objects on display, or the local animals and plants in case of a natural heritage site. Curiosity, humour, and intelligibility are highly important as well as the possibility to ask questions, to which they expect a valid reply. They also would like to have their opinions heard and accepted. One of the respondents would like to pass the waiting time with the help of interactive panels placed at the entrance area and also free Wi-Fi seems to be a basic requirement. In case of natural heritage sites, children would like to meet more wild animals in their natural environment and enrich the trips with obstacle course, adventure parks, or with labyrinths which would also please them.

Involvement is essential, children would like to take part of the story by means of exciting games and contests, interesting physics experiments, revived folk traditions, and historical events. According to them, it would be more impressive to learn about old habits and objects by comparing them to present-day parallels, e.g. if a museum object has a today's equivalent they would like to compare them, to hear about how both are made and used. They are equally enthusiastic about understanding how a tradition changes over the centuries or why it finally disappears. Quite a few of the respondents would like to experience the life of historical people. One of the students raised the idea of a camp where they could live in old houses, living the everyday life of the onetime inhabitants, doing the activities they used to do, and practicing the trade related to the building (e.g. mill-miller). Another pupil would gladly participate in archaeological camps, hoping to actually find something valuable which could be exhibited indicating the circumstances and the name of the children who found it.

One of the most popular topics was the question of eating and drinking. In case of a history related exhibition, students would willingly taste the meals and drinks of the given period, not to mention the sweets. Purchased or self-made souvenirs tend to be of the same importance, as it makes the experience tangible and they can recall the memories and share it with their family later on. Purchased souvenirs must be of an affordable price or included in the entrance fee. Finally and to the author's pleasure, some of the respondents mentioned that to make the experience more exciting is not exclusively the task of teachers and that of the site. Children also have to have a positive attitude towards the matter; it is up to them to accept it open-minded and with sympathy to make the experience work.

\section{CONCLUSIONS}

The result of the author's research shows that the overall objectives of public education in Hungary are consistent with the heritage protection goals set up by UNESCO. Both the Law on Public Education and the National Curriculum emphasise the importance of 
educating children to know, to esteem, and to safeguard the cultural heritage. The problem, as always, lies in the realisation. Although the law stipulates the need for site visits, it does not allocate resources, qualified teachers, or the necessary class time. The author believes that the National Curriculum should encourage teachers to consciously build their heritage project into the curriculum of the given academic year while providing the necessary class time. It would be essential to ensure that all children, regardless of the financial situation of their parents, could participate in visits of this kind. Financing such projects is always a delicate topic in Hungary but the necessary resources could be gathered from EU (European Union) funds, endowments, or government funding programmes. The initiative could also be taken by the schools internally within the teaching staff and externally with a nearby heritage site to cooperate on complex, long-term projects. Internal cooperation would also facilitate cross-curricular integration as well as the modification of the timetable necessary for the site visits.

Motivation and training of teachers is another key to success. Teachers who have the ability to make the lessons interesting and to capture the students' attention are the best-liked in school. If he/she involves the students to such projects, he/she can count on their enthusiasm and attention all along the academic year. Courses and educational materials are already available on the internet but the majority of the teachers are not aware of them. If the National Curriculum encouraged the schools to initiate such projects, possibly more schools would benefit from the opportunity. On the other hand, heritage sites should also seek the chance of cooperation with schools. First of all, they should recognise that their long-term survival is not possible without comprehensive heritage education. The author's research revealed that many of these sites offer high quality programmes and related downloadable material but to familiarise teachers with those, sites have to visit the neighbouring schools and draw their attention to the mutual benefits of the cooperation. Finally, it is indispensable to inform the parents and this should be carried out by the schools and teachers as they are in direct contact with them. Families have to be aware of the goals of heritage education and of particular projects and they should support them as far as possible. Heritage education begins in the family and family has an important role in this process even during school years. Parents must understand how the time and money is spent on these projects, because their moral and financial support is needed for reaching the ultimate goal of heritage education, namely to turn the children into conscious, active, and responsible adults caring for the heritage and passing it onto the next generations. In the author's view, circumstances in Hungary are promising in this field; therefore the author hopes we can take this opportunity in order to allow forthcoming generations to be still proud of our rich cultural heritage.

\section{References}

Ágh, Z. 2009. Conclusions of the Introduction of the Version A of Homeland and People Studies. OFI—tudástár. Retrieved March 14, 2016 (http://ofi.hu/tudastar/tantargyak-helyzete/ agh-zsofia-hon).

Angeliki, A. and G. Lepouras. 2008. "A Fast Pace Method for Involving Children in Edutainment." Presented at Technology Design: Proceedings of the 1st International Conference on Advances in Computer Human Interaction, St. Luce, Martinique, February 10-15, pp. 149-157.

Bárd, E. 2009. "National Survey on Schools' Usage of Museums." In Musem Compass 3, edited by T. Vásárhelyi. Szentendre: MOKK.

Bassa, L. 2014. "Difficulties of Heritage Education.” Presented at Science Day 2014 Conference, Budapest: Budapesti Kommunikációs és Üzleti Főiskola, November 19.

Bilku, R. 2009. Forest School. OFI Tudástár. Retrieved (http://mkne.hu/iz_irasok/erdeiisk.pdf).

De Troyer, V., J. Vermeersch, H. van Genechten, K. Kosters, N. Vitré, P. Mols, ... F. Pizzicannella. 2005. Heritage in the Classroom: A Practical Manual for Teachers. Antwerp: Garant.

Elekházy, N. 2009. Forest Schools in Hungary-Interpretation. 
Parliament Library-Research Service. Retrieved February 18, 2016 (http://www.parlament.hu/biz38/korb/dok/erdei_ iskola.pdf).

Karácsony Molnár, E. and M. Kraicini Szokoly. 1998. Homeland and People Studies, Folklore in Education. Budapest: Budapest Teacher Training College.

Karlovitz, J. 2009. The National Curriculum's Aspects and Opportunities in Museum Education. Pp. 28-37 in Museum Compass 3, edited by T. Vásárhelyi. Szentendre: MOKK.

Németh, A. 2009. "Legal Backgrounds of Museum Visits in Public.” In Museum Compass 3, edited by T. Vásárhelyi. Szentendre: MOKK.

Treiber, P. 2009. Obstacles to the Museum Visit. Pp. 98-102 in Museum Compass 3, edited by T. Vásárhelyi. Szentendre: MOKK.
United Nations Educational, Scientific, and Cultural Organization. 2002. World Heritage in Young Hands-An Educational Resource Kit for Teachers. Paris: UNESCO.

Vásárhelyi, T. 2009. "Lifelong Learning, School and Museums." Pp. 146-162 in Museum Compass 3, edited by $\mathrm{T}$. Vásárhelyi. Szentendre: MOKK.

\section{Bio}

Krisztina Balázs-Bécsi, MA in Tourism Management, Budapest Metropolitan University of Applied Sciences, Budapest, Hungary, MA in Economics, Université de Picardie Jules Verne, Amiens, France; research fields: heritage tourism, sustainable tourism, heritage education, museum and site interpretation. 